\title{
Efficient Heating Strategies Based On Variable Set-Point Temperature of a Bus Cabin with No Air Recirculation
}

\author{
Ehsan Afrasiabian', Roy Douglas ${ }^{1}$, Gareth Cunningham ${ }^{2}$, Marco Geron ${ }^{1}$ \\ ${ }^{1}$ Queen's University Belfast \\ School of Mechanical \& Aerospace Engineering \\ Stranmillis Road, Belfast BT9 5AH, United Kingdom \\ e.afrasiabian@qub.ac.uk; r.douglas@qub.ac.uk; m.geron@qub.ac.uk \\ ${ }^{2}$ Wrightbus \\ 201 Galgorm Road Ballymena, BT42 1SA, United Kingdom \\ gareth.cunningham@wright-bus.com
}

\begin{abstract}
A coupled model of a generic bus and an all-fresh air Heat Pump (HP) system was developed to investigate the impact of the cabin set-point temperature on the thermal comfort level and the energy consumption of heating. Predicted Mean Vote (PMV) and Predicted Percentage of Dissatisfied (PPD) from Fanger's model were used to quantify the comfort level inside the cabin. Different heating strategies based on fixed and variable set-point temperature were examined for an all-fresh air HP under different outdoor temperatures. The results indicate that for the studied all-fresh air HP, adopting a proper heating strategy based on variable set-point temperature could reduce the power demand up to $61 \%$ when the outdoor temperature is $-5^{\circ} \mathrm{C}$.
\end{abstract}

Keywords: All-fresh air Heat pump, Bus, Comfort level, Variable set-point temperature, COVID-19, Heating strategy

\section{Introduction}

Heating systems in electric buses (EBs) are challenging, as they can potentially be energy-depleting devices that reduce the driving range of EBs. Besides, the use of public transport has become more complicated due to growing concerns about their potential to spread infections from person to person while a large number of people travel within a limited space, especially during contagious disease outbreaks such as the current global coronavirus pandemic (COVID-19). Therefore, it is essential to implement efficient heating control strategies both to meet the safety requirements for on-board people and to reduce energy consumption.

In recent years, Heat Pumps (HPs) have attracted considerable attention for their efficient performance, making them a reasonable substitution for electric heaters in EBs. When using HPs, it is a common practice to employ recirculated air and mix it with fresh air to reduce heating loads. Examples from the literature have shown that utilizing recirculated air can reduce the heating demand by more than $30 \%[1,2]$. However, since we are now living in unprecedented times of the COVID-19 pandemic, the transport operators are taking measures to lower the possibility of the virus spreading and put the safety of the drivers and passengers first. One measure is running HP and air conditioning in all-fresh-air mode and avoid recirculating air inside the cabin, or increase the fresh air ratio as much as possible [3,4]. This is expected to increase the power demand remarkably if the conventional control strategies and common control criteria for the cabin condition do not change. Recently Afrasiabian et [5] al. proposed a recovery HP to avoid air recirculation inside the bus and to recover the waste heat before being vented outside. They analysed the energy-saving potential of the recovery HP, compared to a baseline system. They did not study the comfort level inside the cabin and limited their research into the cases where outdoor and setpoint temperatures were 5 and $17^{\circ} \mathrm{C}$, respectively.

Moreover, several studies have been conducted on efficient strategies to reduce the energy consumption in buses for Heating Ventilation and Air Conditioning (HVAC). For example, O'Boyle et al. [6] suggested that a hysteresis control strategy (cycling between the maximum and lower heating capacities) could reduce the energy consumption by about $27 \%$. Afrasiabian et al. [7] studied both the thermal comfort level and the power demand for a multi-unit AC system in a generic bus. They showed that how the implemented control strategies and criteria could affect energy consumption and thermal comfort. In both studies, the inside set-point and the ambient temperatures were assumed constant. 
In this study, a dynamic model of a heat pump system in a generic bus was developed to investigate the impact of the cabin's set-point temperature on the power demand and the cabin comfort level. Simulink and Simscape toolbox from MATLAB (R2020a) were used to develop the real-time model by integrating an HP with a cabin sub-model. Different control strategies based on fixed and variable set-point temperatures of the cabin were examined to investigate the average power demand and thermal comfort. The comfort level is discussed in terms of Predicted Mean Vote (PMV) and Predicted Percentage of Dissatisfied (PPD) indices.

\section{Methodology}

\subsection{Numerical Model}

Two sub-models, namely one generic bus cabin and one baseline heat pump, were developed and coupled in the MATLAB Simulink environment. As illustrated in figures 1and 2, several physical elements establish Two-Phase (coloured in blue), Moist Air (coloured in purple), and Thermal (coloured in orange) networks. The Two-Phase elements form the HP model that consists of a compressor (comp), an electronic expansion valve (EEV), an accumulator (ACC), sensors, an evaporator, and a condenser. The HP is coupled with the Moist Air through the evaporator and condenser. Both the evaporator and condenser are multi-domain blocks that function as the interface between the refrigerant and the airflow circuits. The Moist Air network represents the cabin as a constant volume chamber with its respective airflows from/to the HP and environment. As depicted in figure 2, a network of contributing thermal elements was built to simulate the heat flow through the system by taking into account the metabolic heat generation $\left(\dot{Q}_{m e t}\right)$, heat storage $\left(\dot{Q}_{m}\right)$, heat transfer through convection, conduction, and radiation between the cabin and environment $\left(\dot{Q}_{s o l}+\dot{Q}_{a m b}\right)$, and the heat loss through the vents $\left(\dot{Q}_{\text {vent }}\right)$, as described by Eq.1.

$$
m_{a} c_{p, a} \frac{d T_{c a b}}{d t}=-\dot{Q}_{m}+\dot{Q}_{s o l}+\dot{Q}_{a m b}+\dot{Q}_{m e t}+\dot{Q}_{v e n t}+\dot{Q}_{H P}
$$

In the present study, metabolic water vapour generation is also taken into account (for more details see [5]), the solar term is ignored in the wintertime, the cold bridge effect is neglected, and so the conductive $(k)$ and convective $(h)$ heat transfer coefficients are uniform throughout their respective media, as listed in Table 1. The model is verified through the comparison of the heating capacity and COP of the HP system with the results predicted by CoolPack toolkit V1.5, with less than $2 \%$ error (for more details on the verification methodology see [7]).

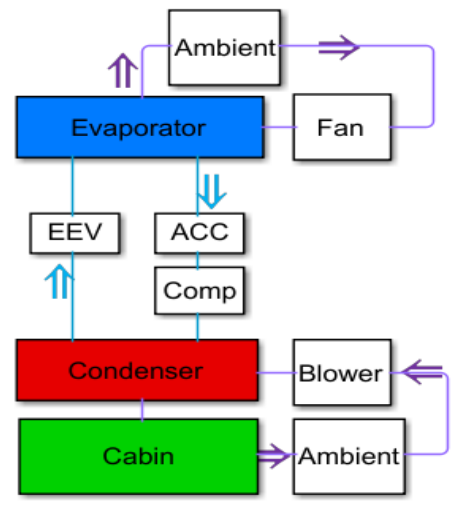

Figure 1: Schematic of the coupled model

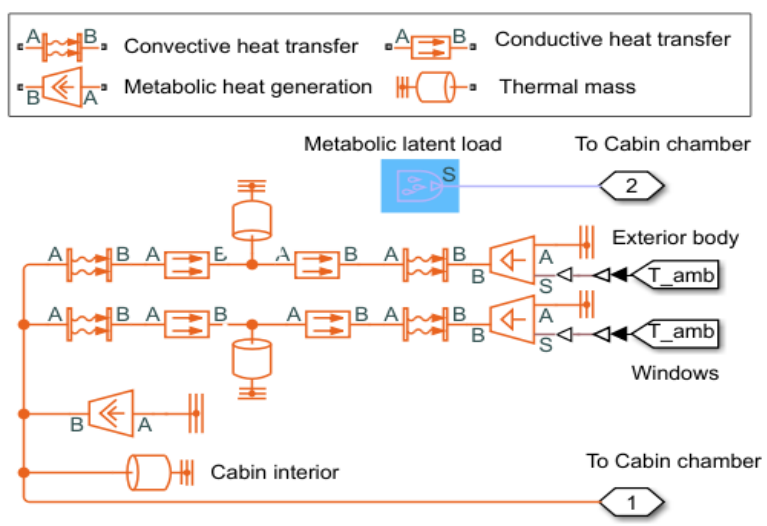

Figure 2: Schematic of the thermal network

\subsection{Comfort Level}

To quantify the comfort level inside the cabin two indices from Fanger's model [8], namely Predicted Mean Vote (PMV) and Predicted Percentage of Dissatisfied (PPD), were used. These two indices were initially proposed for steadystate and uniform conditions but have been widely used to evaluate the thermal comfort level in passenger vehicles and public transport systems $[9,10,11,12]$. PMV predicts the mean of a large group of people's votes on a seven-point thermal sensation scale, as \pm 3 (hot/cold), \pm 2 (warm/cool), \pm 1 (slightly warm/ slightly cool), and 0 (thermally neutral sensation). PMV is a function of the average metabolic rate (here is $70 \mathrm{~W} / \mathrm{m}^{2}$ ), air temperature, relative humidity $(R H)$, clothes thermal insulation ( $\mathrm{clo}$ ), mean radiant temperature, and air velocity ( here is $0.1 \mathrm{~m} / \mathrm{s}$ ). In this study, the outdoor 
clothing insulation in winter ranges from 1.25 to 3.25. On top of that, PPD establishes a quantitative prediction of the percentage of people who are thermally dissatisfied and reads as:

$$
P P D=100-95 \cdot \exp \left(-\left(0.03353 \cdot P M V^{4}+0.2179 \cdot P M V^{2}\right)\right)
$$

In this paper, two classes of comfort level are considered acceptable. The first one is recommended by ISO 7730 standard when $-0.7<P M V<0.7$ as the minimum acceptable PMV range for indoor spaces. The other one is when $-1<P M V<$ +1 , indicating that the thermal sensation is neutral or just slightly cool/warm.

\section{Results and Discussion}

We investigated how the determination of the set-point temperature $\left(T_{\text {set }}\right)$ in different ambient temperatures $\left(T_{a m b}\right)$ can affect both the thermal comfort inside the cabin and energy consumption. Considering the fact that usually, people in colder weathers put on more clothes with higher ensemble clos, it makes sense to reduce $T_{\text {set }}$ inside the cabin as the outdoor temperature declines. So people would feel comfortable without reducing the clothing level. It might help to reduce the energy consumption, especially for all-fresh air systems where waste heat through vents is higher than other systems with air recirculation. Table 2 shows different scenarios based on different $T_{a m b}$ and $T_{\text {set }}$ as well as their averaged power demand with respect to a reference case (C.1). Here, A, B, and C scenarios represent different outdoor temperatures of $+5,0$, and -5 ${ }^{\circ} \mathrm{C}$. For A.1, B.1, and C.1 the set-point temperature is $17^{\circ} \mathrm{C}$, in B.2 and C.2 the set-point is $12^{\circ} \mathrm{C}$, and for C. 3 it equals $7{ }^{\circ} \mathrm{C}$ inside the cabin. C.1 is the most energy intensive case with the highest temperature difference $\left(\Delta T=T_{s e t}-T_{a m b}\right)$ of $22^{\circ} \mathrm{C}$. In B. 1 and C. 2 this difference is $17^{\circ} \mathrm{C}$ and in A.1, B.2, and C.3 cases $\Delta T=12^{\circ} \mathrm{C}$. As the results show the power demand (defrosting is excluded) in different ambient temperatures but with the same $\Delta T$ would almost be the same. Lowering $\Delta T$ to $17^{\circ} \mathrm{C}$ would reduce the power demand by about $34 \%$ in C.2 (\& B.1), with respect to C. 1 case. If $\Delta T=12^{\circ} \mathrm{C}$ the average power demand would drastically drop by about $61 \%$. Therefore power demand-wise, lowering the set-point temperature could be a good strategy to heat the cabin in colder weathers.

Table 1: Model parameters

\begin{tabular}{|l|l|}
\hline \multicolumn{1}{|c|}{ No. Passengers } & 14 \\
\hline$k_{\text {body }} \& k_{\text {glass }}[\mathrm{W} / \mathrm{m} . \mathrm{K}]$ & $0.35 \& 0.75$ \\
\hline$h_{\text {external }} \& h_{\text {internal }}\left[\mathrm{W} / \mathrm{m}^{2} . \mathrm{K}\right]$ & $25 \& 5$ \\
\hline Bus size $(L \times W \times H)\left[\mathrm{m}^{3}\right]$ & $10 \times 2.5 \times 3$ \\
\hline$V_{\text {Blowers }} \& V_{\text {Fans }}\left[\mathrm{m}^{3} / \mathrm{hr}\right]$ & $900 \& 3600$ \\
\hline$T_{\text {initial }} \& \mathrm{RH}_{\text {initial }}\left[{ }^{\circ} \mathrm{C} \& \%\right]$ & $T_{\text {set }}-7 \& 50$ \\
\hline
\end{tabular}

Table 2: Average power demand for different heating control scenarios

\begin{tabular}{|c|c|c|c|}
\hline Scenario & $\boldsymbol{T}_{\boldsymbol{a m b} \boldsymbol{b}}(\boldsymbol{C})$ & $\boldsymbol{T}_{\boldsymbol{s e t}}(\boldsymbol{C})$ & $\boldsymbol{W}_{\boldsymbol{a v}}(\%)$ \\
\hline A.1 & 5.00 & 17.00 & -61.69 \\
\hline B.1 & 0.00 & 17.00 & -34.88 \\
\hline B.2 & 0.00 & 12.00 & -61.52 \\
\hline C.1 & -5.00 & 17.00 & 0.00 \\
\hline C.2 & -5.00 & 12.00 & -34.25 \\
\hline C.3 & -5.00 & 7.00 & -60.61 \\
\hline
\end{tabular}

Table 3: PMV and PPD vs. clothing insulations (clo)

\begin{tabular}{|c|c|c|c|c|c|c|c|c|c|}
\hline \multirow{2}{*}{ Scenario } & \multicolumn{9}{|c|}{ PMV } \\
\hline & 3.25 (clo) & 3.00 & 2.75 & 2.50 & 2.25 & 2.00 & 1.75 & 1.50 & 1.25 \\
\hline A.1 & 0.49 & 0.38 & 0.25 & 0.10 & -0.08 & -0.28 & -0.53 & -0.83 & -1.20 \\
\hline B.1 & 0.38 & 0.26 & 0.12 & -0.04 & -0.22 & -0.43 & -0.69 & -1.00 & -1.39 \\
\hline B. 2 & 0.02 & -0.12 & -0.28 & -0.47 & -0.69 & -0.94 & -1.24 & -1.61 & -2.07 \\
\hline C.1 & 0.29 & 0.17 & 0.03 & -0.14 & -0.32 & -0.55 & -0.81 & -1.14 & -1.54 \\
\hline C.2 & -0.09 & -0.24 & -0.41 & -0.60 & -0.82 & -1.09 & -1.40 & -1.78 & -2.25 \\
\hline C.3 & -0.45 & -0.61 & -0.81 & -1.03 & -1.28 & -1.58 & -1.94 & -2.38 & -2.94 \\
\hline \multirow{2}{*}{ Scenario } & \multicolumn{9}{|c|}{ PPD } \\
\hline & 3.25 (clo) & 3.00 & 2.75 & 2.50 & 2.25 & 2.00 & 1.75 & 1.50 & 1.25 \\
\hline A.1 & 10.19 & 8.09 & 6.37 & 5.30 & 5.25 & 6.82 & 11.05 & 19.67 & 35.34 \\
\hline B.1 & 8.04 & 6.44 & 5.37 & 5.10 & 6.08 & 9.04 & 15.18 & 26.41 & 45.10 \\
\hline B. 2 & 5.08 & 5.40 & 6.78 & 9.74 & 15.04 & 23.82 & 37.48 & 56.88 & 79.40 \\
\hline C.1 & 6.85 & 5.66 & 5.09 & 5.47 & 7.29 & 11.39 & 19.08 & 32.29 & 52.83 \\
\hline C. 2 & 5.22 & 6.22 & 8.49 & 12.58 & 19.34 & 29.92 & 45.50 & 65.91 & 86.52 \\
\hline C.3 & 9.22 & 13.01 & 18.80 & 27.35 & 39.43 & 55.40 & 73.88 & 90.26 & 98.70 \\
\hline
\end{tabular}

Moreover, table 3 illustrates the calculated PMVs and their respective PPDs for different scenarios and different clothing insulation levels $(\mathrm{clo})$, over six hours. The green circles show the cases that satisfy ISO 7730 standard $(-0.7<P M V<0.7)$, the yellow circles indicate that $-1<P M V<+1$, and the red circles imply that the comfort level is not within the acceptable ranges in this study. These results show that for $T_{a m b}=0{ }^{\circ} \mathrm{C}, T_{\text {set }}=12^{\circ} \mathrm{C}$ could be enough if $\mathrm{clo} \geq 2$ to meet the condition of $-1<P M V<1$ (and clo $\geq 2.25$ for ISO 7730 standard). It indicates that approximately less than 15 and $24 \%$ of people would feel discomfort when clo $\geq 2.25$ and $\geq 2$, respectively. For $T_{a m b}=-5^{\circ} \mathrm{C}$, the lower the set-point temperature, the higher needed clo for reaching the comfort level. As the figure shows for C. 2 and C. 3 cases, clo should be at least 2.5 and 3 to meet ISO 7730 standard.

\section{Conclusion}


In the present work, we numerically investigated how reducing the set-point temperature affects the comfort level inside a generic bus cabin and the power demand. Three different ambient temperatures were examined ranging from -5 to $+5{ }^{\circ} \mathrm{C}$. Results show that for $T_{a m b}=-5{ }^{\circ} \mathrm{C}$ the set-point temperature could be reduced to $+7{ }^{\circ} \mathrm{C}$, if $2.75 \leq$ clo $\leq$ 3 , which is within the reported outdoor insulation level for wintertime. Moreover, results show that adopting variable set-point temperature instead of a fixed one could reduce the needed power by at most $61 \%$ for $T_{a m b}=-5^{\circ} \mathrm{C}$.

In this study, the comfort level was obtained using the PMV and PPD indices that are genuinely proposed for uniform conditions, which is in line with the adopted lumped-model for the cabin. However, further investigations could usefully clarify the impact of non-uniform distribution of the contributing parameters (such as the temperature and air velocity) on the comfort level. Despite this limitation, the presented results show the potential of adopting variable setpoint temperature to provide the passengers with comfortable cabin condition along with the remarkable reduction in power demand for all-fresh air HP systems.

\section{Acknowledgements}

This work was supported by the Northern Ireland Department for the Economy (DfE), Innovate UK and Wrightbus.

\section{References}

[1] P. Leyan, C. Liu, Z. Zhang, T. Wang, J. Shi and J. Chen, "Energy-saving effect of utilizing recirculated air in electric vehicle air conditioning system," International Journal of Refrigeration, vol. 102, pp. 122-129, 2019.

[2] Z. Guiying, H. Zou, F. Qin, Q. Xue and C. Tian, "Investigation on an improved heat pump AC system with the view of return air utilization and anti-fogging for electric vehicles," Applied Thermal Engineering, vol. 115, pp. 726-735, 2017.

[3] U. K. Department for Transport (DfT), "Guidance Coronavirus (COVID-19): safer transport guidance for operators," [Online]. Available: https://www.gov.uk/government/publications/coronavirus-covid-19-safer-transport-guidancefor-operators/coronavirus-covid-19-safer-transport-guidance-for-operators. [Accessed 08 March 2021].

[4] "(CDC), The US Centers for Disease Control and Prevention. Ventilation in Buildings; Considerations to Improve Ventilation," [Online]. Available: https:/www.cdc.gov/coronavirus/2019-ncov/community/ventilation.html. [Accessed 09 March 2020].

[5] E. Afrasiabian, R. Douglas and R. Best, "Dynamic modelling and performance prediction of a recovery fresh air heat pump for a generic bus," in In 2020 Fifteenth International Conference on Ecological Vehicles and Renewable Energies (EVER), pp. 1-5..

[6] C. O’Boyle, R. Douglas, R. Best and M. Geron, "Vehicle Thermal Modelling for Improved Drive Cycle Analysis of a Generic City Bus," In 2020 5th International Conference on Smart and Sustainable Technologies (SpliTech), pp. 1-5. IEEE, 2020.

[7] E. Afrasiabian, R. Douglas and R. Best, "Dynamic Modelling and Performance Prediction of a Multi-unit Baseline Air Conditioning System for a Generic Bus under Part-Load Conditions," SAE Int. J. Commer. Veh., vol. 14, no. $2,2021$.

[8] P. O. Fanger, "Thermal comfort. Analysis and applications in environmental engineering," Thermal comfort. Analysis and applications in environmental engineering, 1970.

[9] K. Zhang, K. Zhou and F. Zhang, "Evaluating bus transit performance of Chinese cities: developing an overall bus comfort model," Transportation Research Part A: Policy and Practice, vol. 69, pp. 105-112, 2014.

[10] I. Cvok, I. Ratković and J. Deur, "Multi-Objective Optimisation-Based Design of an Electric Vehicle Cabin Heating Control System for Improved Thermal Comfort and Driving Range," Energies, vol. 14, no. 4, p. 1203, 2021.

[11] Y. Xie, Z. Liu, K. Li, J. Liu, Y. Zhang, D. Dan, C. Wu, P. Wang and X. Wang, “An improved intelligent model predictive controller for cooling system of electric vehicle," Applied Thermal Engineering, vol. 182, p. 1160, 2021.

[12] J. H. Moon, J. W. Lee, C. H. Jeong and S. H. Lee, "Thermal comfort analysis in a passenger compartment considering the solar radiation effect," International journal of thermal sciences, vol. 107, pp. 77-88, 2016. 